\title{
SPACE TECHNOLOGIES FOR STUDYING AND MONITORING OF SEISMOGENIC ZONES
}

\author{
Dimitar Dimitrov \\ National Institute of Geophysics, Geodesy and Geography - Bulgarian Academy \\ of Sciences \\ e-mail: clgdimi@bas.bg
}

\begin{abstract}
In the present article are produced the results of studies, carried out by the author or by teams under his direction and participation, in different seismogenic zones in Bulgaria and abroad. The submitted cases of the application of space technologies GNSS and InSAR for investigation and monitoring of seismogenic zones manifest the significance and the advantages of these methods in a determination of the regularities in the development of the tectonic processes of accumulation and release of tensions in the seismogenic zones, related to the assessment of the seismic hazard and medium-term forecast of strong earthquakes.
\end{abstract}

\section{Introduction}

The Global Earth Observation System of Systems (GEOSS) and the Copernicus Programme (formerly Global Monitoring for Environment and Security - GMES) have as a priority in the preservation of the environment and the sustainable development of the society - instruments for assessment, as well as methods for monitoring and prognosis.

The seismogenic zones are the region genetically connected to historical and instrumental seismicity, a potential seismic hazard of strong earthquakes and are identified by seismologic, geophysical and geological data. Bulgaria is situated in an active seismogenic zone from which results a main task for the science to study the processes occurring in these zones which lead to strong earthquakes and to undertake appropriate measures for effective counteraction.

This problem is characterized with special topical degree in a national and planetary scale and puts it in the category of the priority research trends in the field of Earth sciences.

The application of space technologies in the Global Navigation Satellite System (GNSS) and the radar Interferometry InSAR (Interferometric Synthetic Aperture Radar) allow to study the seismogenic zones and the physical processes causing the strong earthquakes. The permanent and periodic high precision 
measurement with GNSS and the application of the radar interferometry InSAR are the most effective space technics for monitoring and study of seismogenic zones.

Here below are represented the results of the studies carried out during the last 20 years by the author and groups under his guidance or with his participation in different seismogenic zones in Bulgaria and all over the world [12].

\section{Monitoring of the seismogenic zone in the region of Sofia city}

The region in south of Sofia city is revealed in structure-geomorphologic, tectonic and seismic approach seismogenic zone where could be expected strong earthquakes [1]. This zone is connected to the so-called Vitosha fault dividing Vitosha morphoblock from the absorbed under neogenic sediments complex broke up Sofia graben. The surface manifestations of Vitosha and Lozen faults are presented on the remotely-sensed image, by appointed with InSAR method, relatively vertical deformations and the network for GNSS monitoring (Fig. 1).

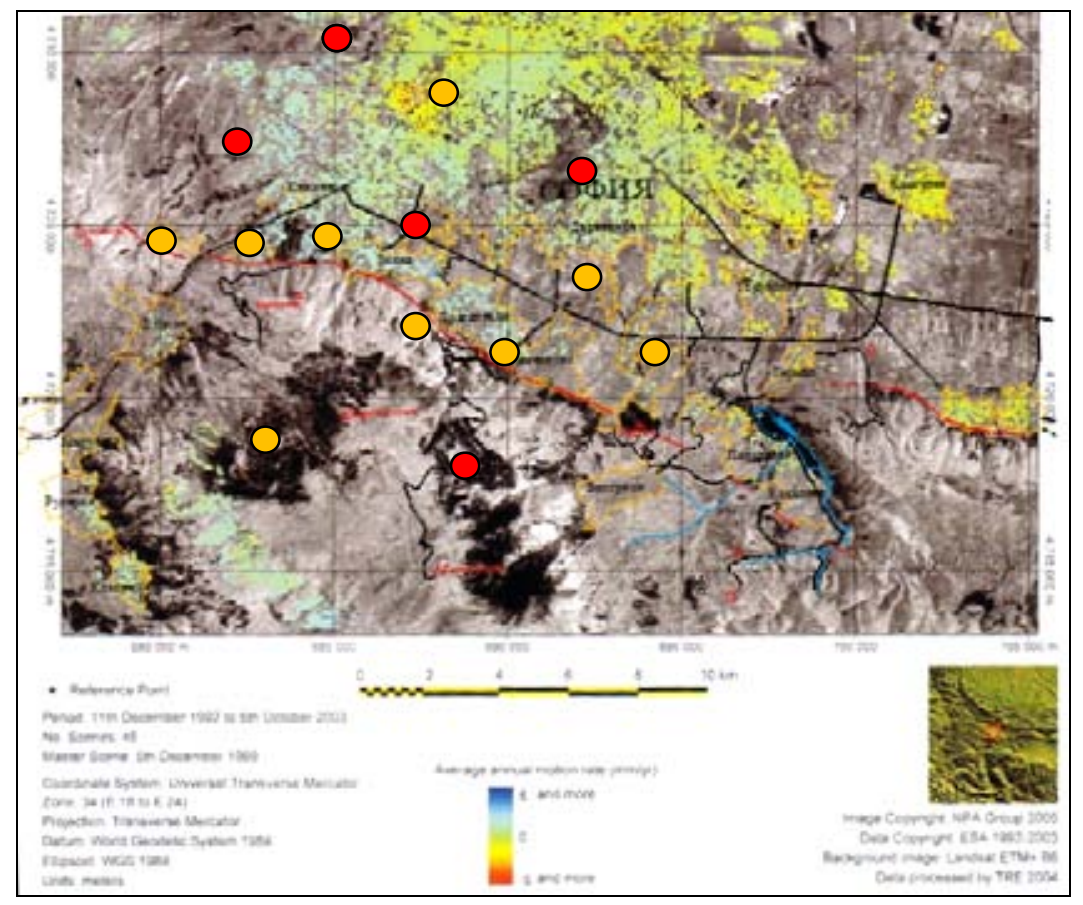

Fig. 1. Network for GNSS monitoring of the Vitosha fault on the remote sensing image and the result of the In SAR study of the zone. The permanent GNSS stations are presented with red and the periodic measurements with orange circles. 

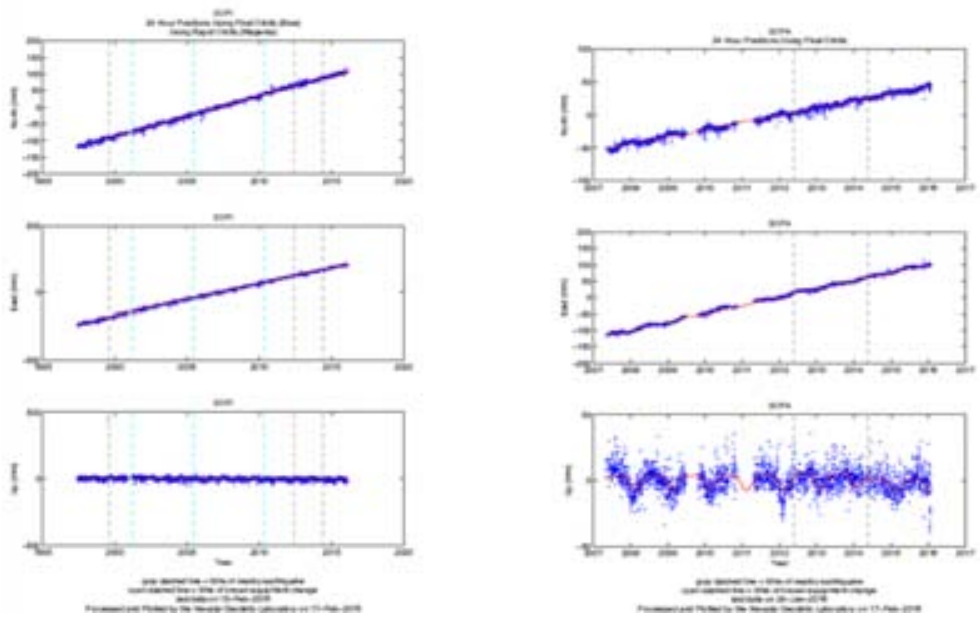

Fig. 2. Components of the absolute velocities from the permanent stations of SOFI and SOFA, on both sides of the Vitosha fault

The obtained from the monitoring identical velocities of displacements of the permanent and periodic measurement GPS stations (Fig. 2) of the order of $1 \div 2 \mathrm{~mm}$ /year do not testify for accumulating of considerable tectonic tensions on Vitosha fault. The data from the permanent and periodic re-measurement GPS stations in the regions provide a high-precision monitoring of the movements in this seimogenic zone in connection with the study of tectonic tensions and seismic hazard [2].

\section{Studies and monitoring of the seismogenic zone Chirpan-Plovdiv}

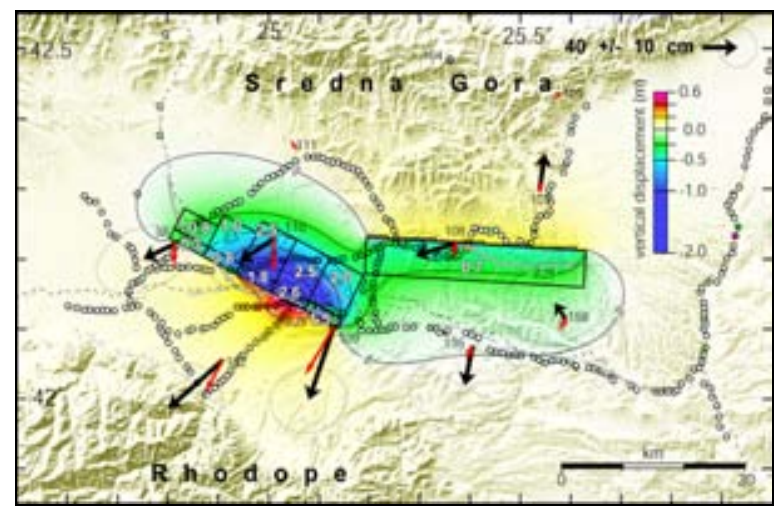

Fig. 3. Main faults activated during the earthquakes on 14 and 18 April 1928, obtained from modeling of the co-seismic displacements determined by data from GNSS measurements (black arrows) 

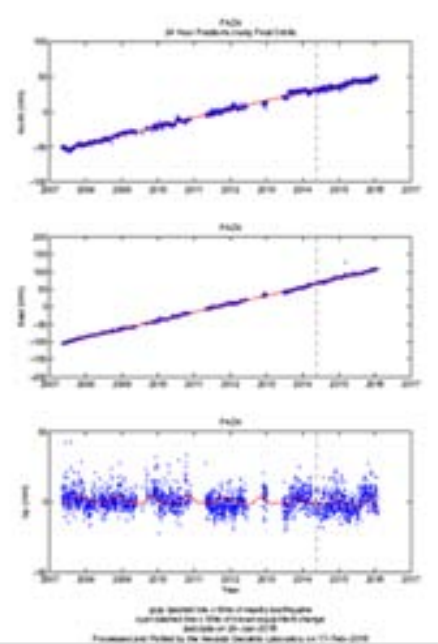
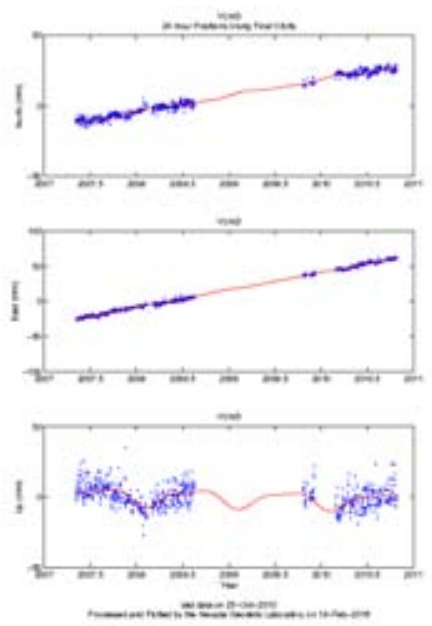

Fig. 4. On the right is a permanent GNSS station in the city of PAZA and YUND the components of its temporary series

The application of the space technology GNSS for assessment of the velocities of shifting of geodetic benchmarks in the region allow to study the zone and to determine the geodetic parameters of the main faults, activated in 1928 [3] (Fig. 3). The monitoring of the zone with periodic GNSS measurements (Fig. 4) provides an assessment of the tectonic tensions and along with paleoseismic studies allows for determination of the seismic cycle of strong earthquakes in the region [4].

\section{Studies and monitoring of the seismic zone of South-West Bulgaria}

The region of South-West Bulgaria is known with one of the strongest earthquakes which struck Europe on 4 April 1904 with magnitude (M) 7.3 and $7.8[1]$.

The continuous monitoring of the zone with permanent GNSS stations and periodic measurements of the local geodynamic network around Krupnik fault allow to assess the regional tectonic movements and local tensions around Krupnik fault (Fig.5). According to the data obtained and together with the results from the paleoseimologic studies was determined the seismic cycle of the Krupnik fault [5]. 

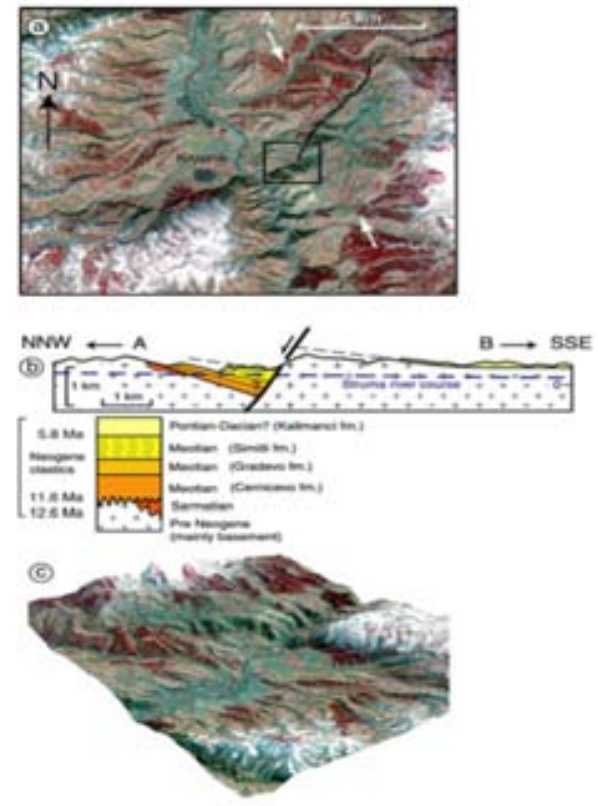
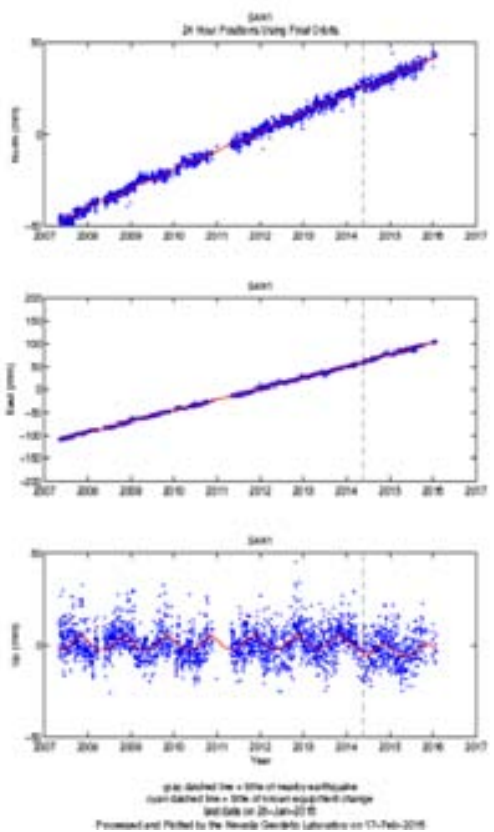

Fig. 5. The Krupnik fault mapped on a remotely sensed image, geologic cross profile and components of absolute velocities of the permanent GNSS stations Sandanski

\section{Studies of seismogenic zones in Central Greece}

The Corinth Bay in Central Greece is one of the most active internal continental structures in Europe. This asymmetric graben is surrounded from active faults causing many catastrophic earthquakes (Aigion, 1861, $\mathrm{M}=7.0$; Corinth, 1981, $M=6.7$ ). Since 1991 in this zone is carried out a monitoring of the surface deformations with GNSS network from 22 permanent and 240 periodic pre-measurement stations. It was established a stretching of the bay with medium velocity of $14 \div 15 \mathrm{~mm} /$ year.

5.1. For the study of the earthquake on 15.06.1995 have been used remote sensing data and GNSS and InSAR methods (Fig. 6).

On the Fig. 6 are presented co-seismic displacements from the earthquake of 1995 of 24 benchmarks, assessed by GNSS measurements, as well as co-seismic deformations from InSAR study. The modeling of the obtained co-seismic displacements allows accessing the geometric seismotectonic parameters of the main faults of the main shock [2]. 

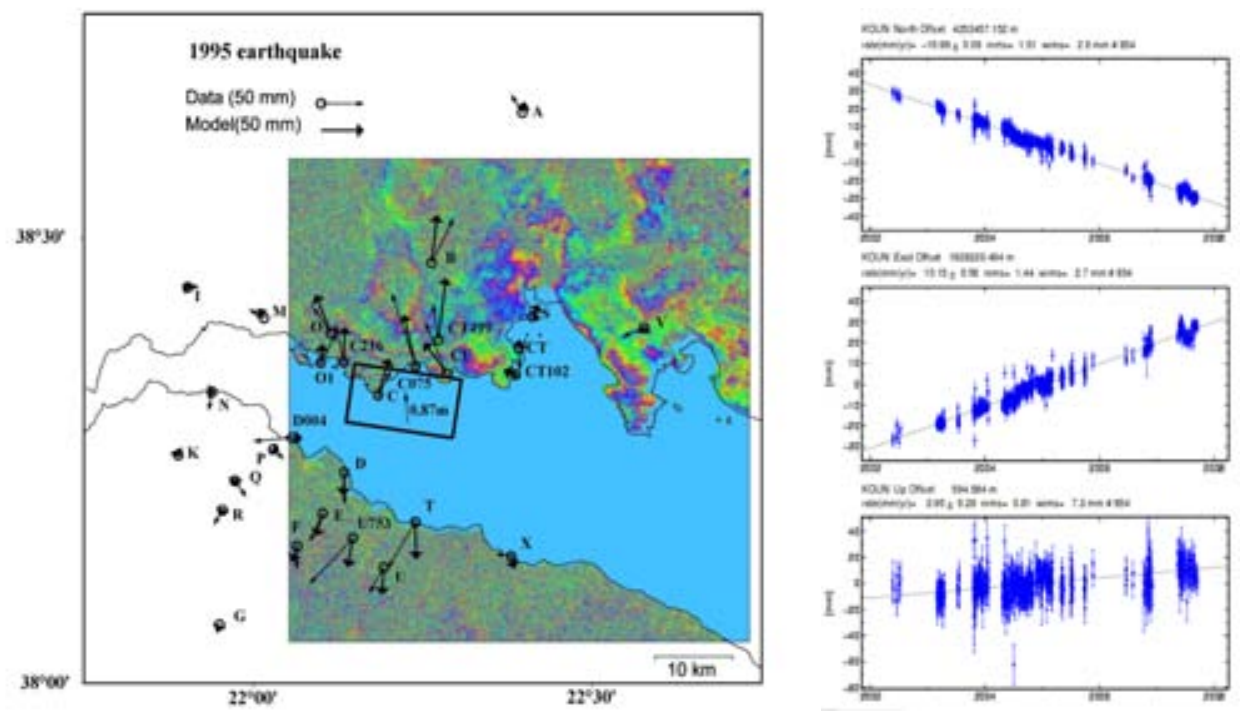

Fig. 6. The region of the earthquake on 15.06.1995 with determined co-seismic deformations by GNSS and InSAR methods. The assessed and modelled displacements are presented respectively by thin and thick arrows. On the right is presented a comparison between permanent stations on the two coasts of Corinth Bay. The space vectors between the stations on the two coasts of the bay has been struck.

5.2. In the study of the earthquake on 26.07 .1996 in Konitsa $M=5.3$ in Northern Greece was confirmed the possibilities of the method InSAR for the study of the physical mechanisms of medium-strong earthquakes with (Fig. 7).
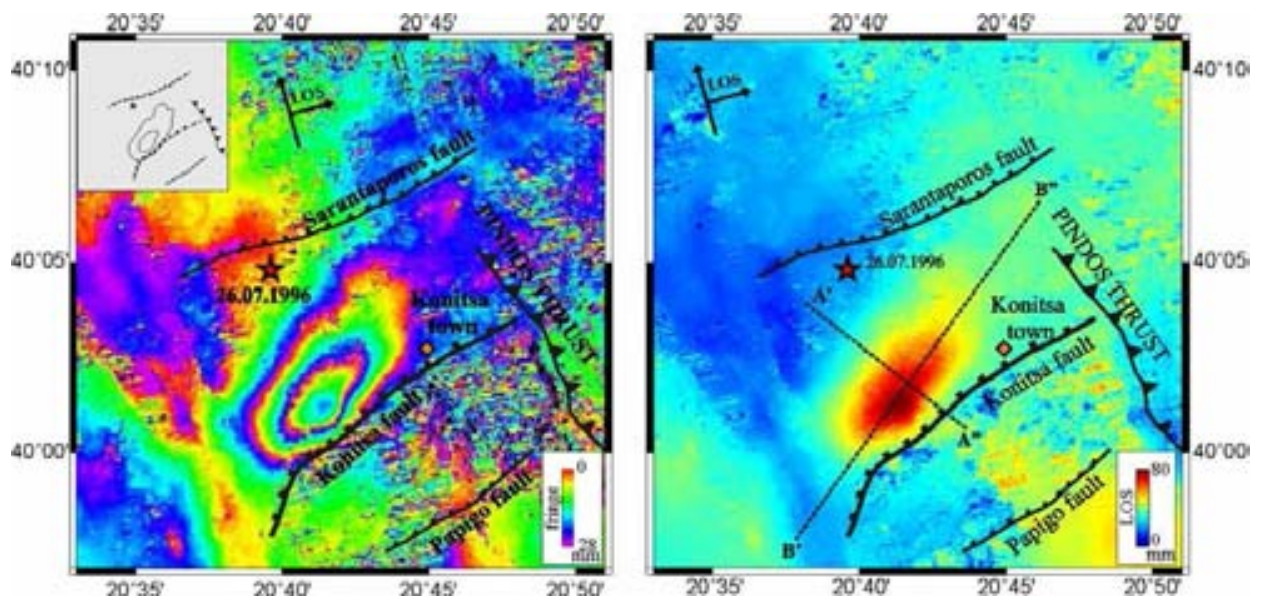

Fig. 7. Seismogenic zone of town of Konitsa with the assessed by the method InSAR co-seismic deformations of the earthquake in 1996 and the faults activated 
5.3. The study of the earthquake of 2003 in Lefkada $M=6.3$ by InSAR method and modeling of co-seismic deformations (Fig. 8) shows the possibilities of this method for assessment of the place and the seismotectonic parameters of the activated sea faults [6].
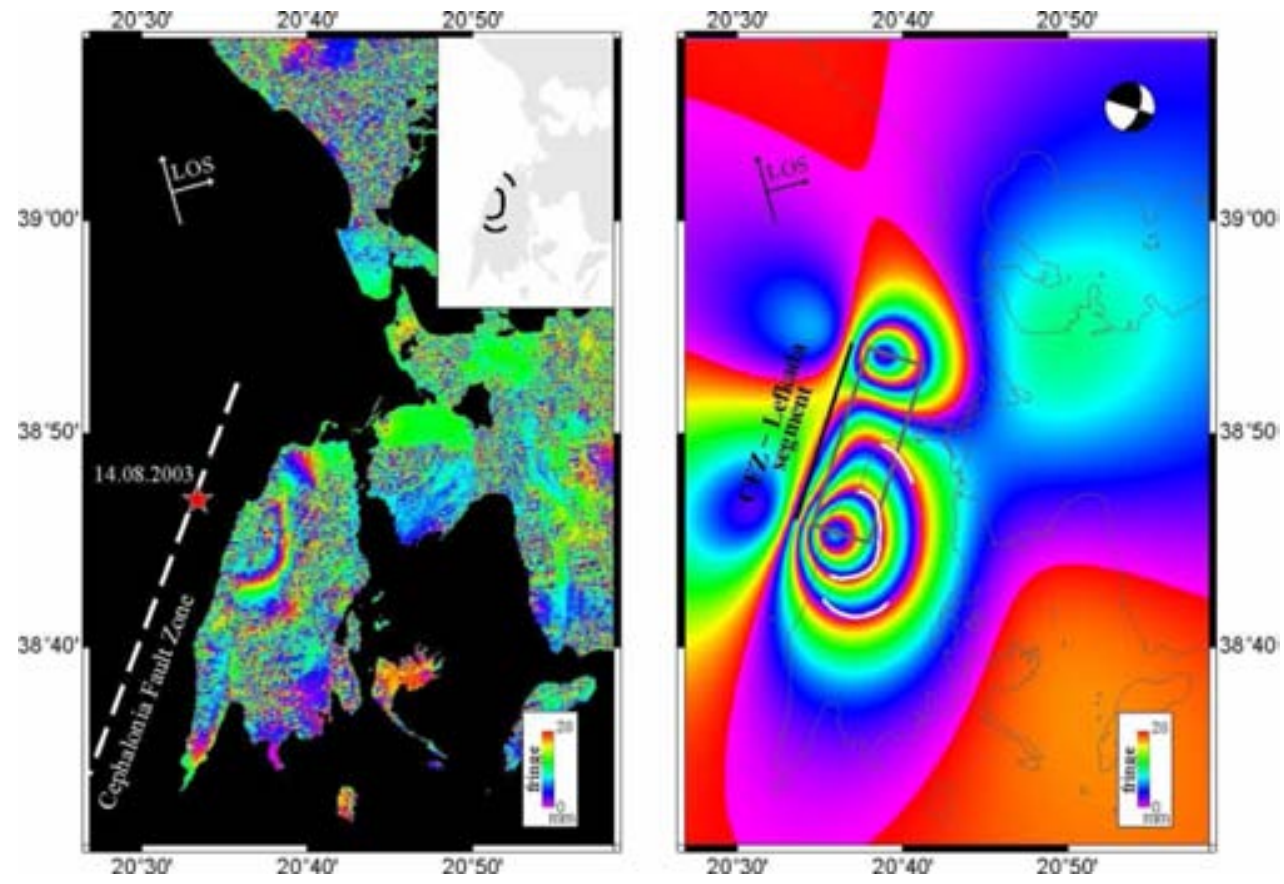

Fig. 8. Isle Lefkada with the assessed by the method InSAR coseismic deformations and the fault, activated during the shock of 2003. On the right - the model of coseismic deformations.

\section{Study of the zone of the earthquake of 1835 in Central Chile}

The seashore line of Chile is one of the most seismogenic zones in the world. Here approximately at every ten years occur strong earthquakes with magnitude $\mathrm{M}>8$. The region is situated between $35^{\circ}$ and $37^{\circ} \mathrm{S}$ and is known with a very strong earthquake of February 1835 [7] with $\mathrm{M}=8,5$ [8] (Fig. 9).

In this region was stabilized and assessed in 1996, 1999 and 2002, with a GNSS network of 41 observation points, which allow considerable displacements of monitoring stations reflected by the accumulation of the inter-seismic tensions caused by plate subduction. 

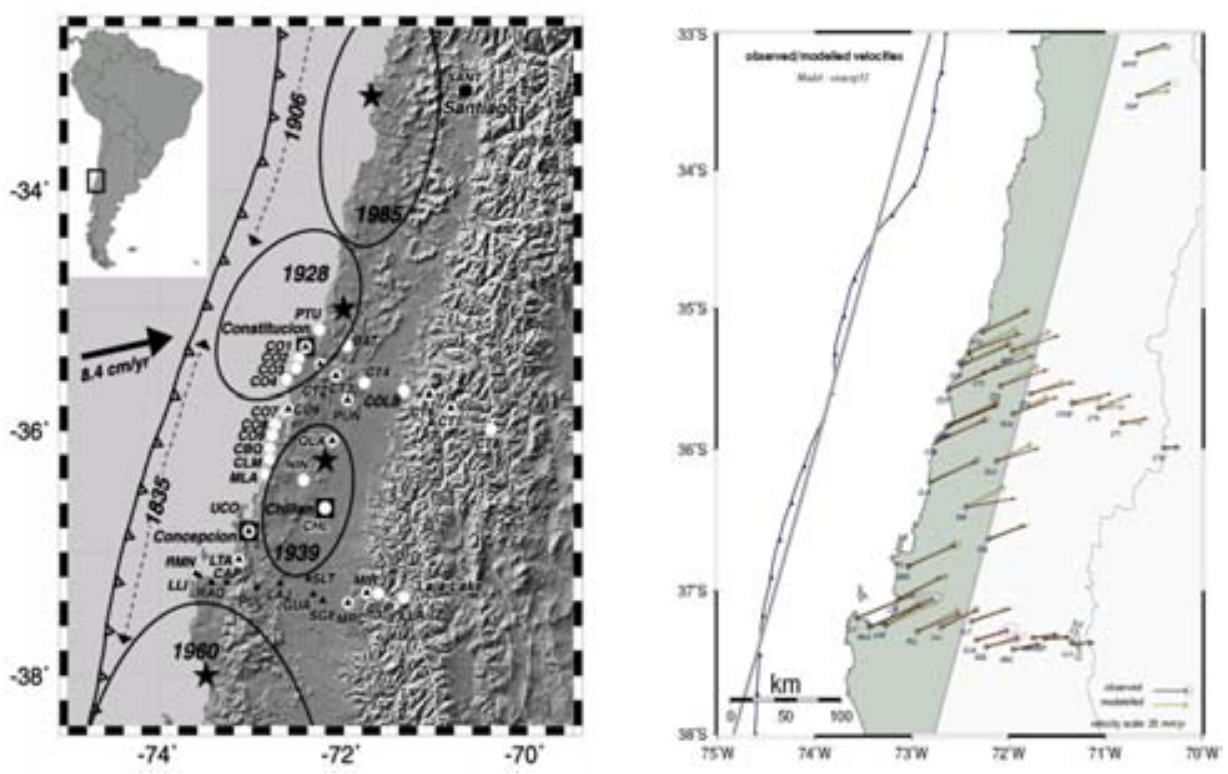

Fig. 9. Geodynamic GNSS network of 41 observation points in the seismogenic zone of central Chile with the results of monitoring 1996, 1999 and 2002. On the right

(in greyscale) - the zone of collision of the Pacific Nazca Plate with this of South America-obtained from the modeling of interseismic displacements.

The analysis of the results from three cycles of measurements determines considerable inter-seismic movements with velocity from 34 to $45 \mathrm{~mm} /$ year on coastline and from 10 to $20 \mathrm{~mm} /$ year on the mountain range of Andes in comparison with the stable part of the South American continental Plate (Fig. 9). Namely, the considerable difference between velocities of movement of the benchmarks stabilized on the coastline and those on the mighty mountain range of Andes is the reason for the accumulation of the seismogenic tensions in the area up to the contact zone. The data obtained allows assessing exactly the place and

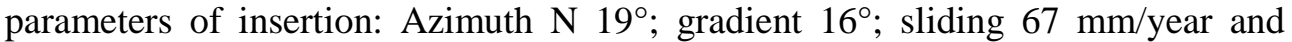
depth of shock $55 \mathrm{~km}$. The results show that the earthquakes in this zone are not simply a kind of subduction and between the subduction zone and the mighty mountain range of Andes are accumulating tensions, increasing the danger of a new strong earthquake [9].

According to the parameters obtained has been calculated the accumulated tectonic tension in the region of the last strong earthquake in 1835 with $\mathrm{M}=8.5$. On its basis was made a forecast for an expected strong earthquake in the zone with $M>8.5$ [9]. The forecast, of the occurring in the study zone earthquake in March 2010 with $\mathrm{M}=8.8$, was cited in [10] as "a good example and successful forecast of strong earthquakes on the basis of scientific data and methodology". 


\section{Monitoring and study of East-Mediterranean area}

For present-day kinematics of central and East-Mediterranean area, implications of the space technologies such as GPS, shows the importance and advantages in establishing of crustal dynamics and mantle flow [11]. Fig. 10 depicts the continuous velocities and strain-rate fields by interpolating geodetic velocities from the 30-years of GPS monitoring in the region, including recent data in the Balkans.

Relative motion between stable Eurasia and the western Aegean Sea is gradually accommodated by distributed N-S extension from Southern Balkans to the Eastern Corinth Gulf. The westward propagation of the North Anatolian Fault (NAF) terminates in the north Aegean and that N-S extension localized in the Corinth Gulf and distributed in Southern Balkans is due to the retreat of the Hellenic slab.

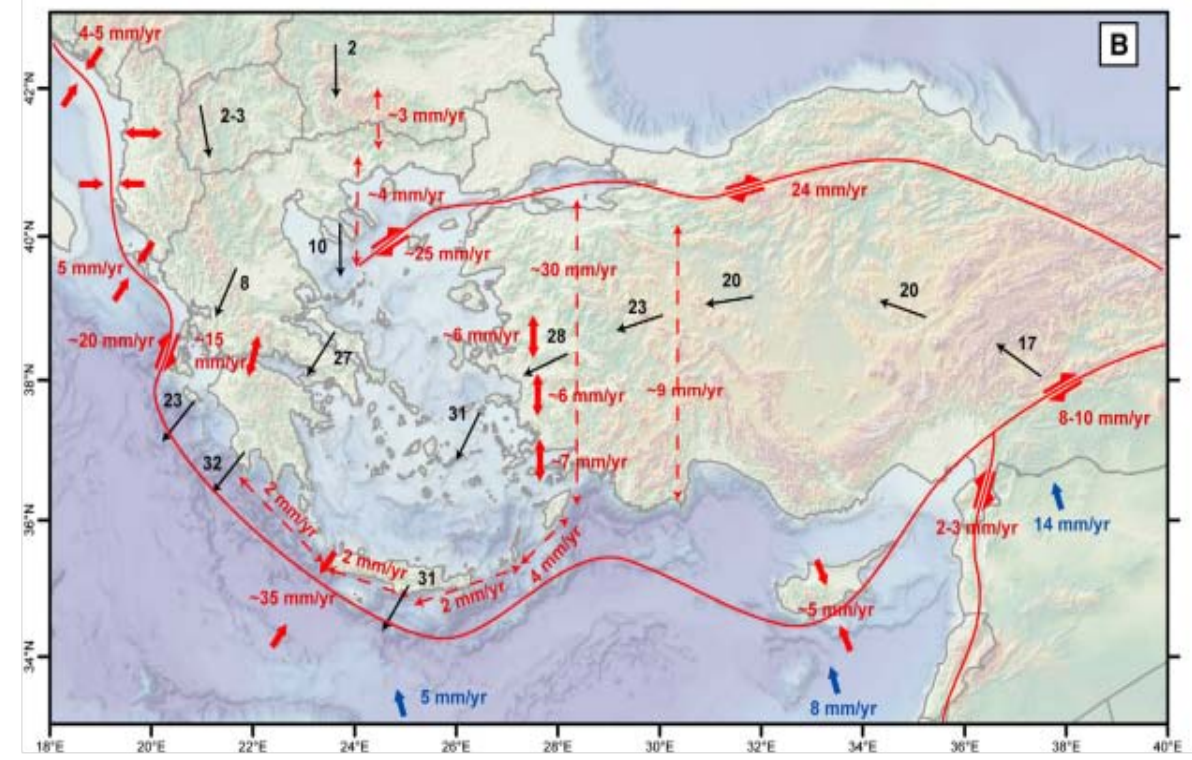

Fig. 10. Velocities and stain from the 30 years GPS monitoring of Central and Eastern Mediterranean region

Present-day kinematics and tectonic map, encompassing the Central and eastern Mediterranean, summarizing the main results and interpretation is presenting on Fig. 11. Kinematic model includes rigid-block motions as well as localized and distributed strain. 


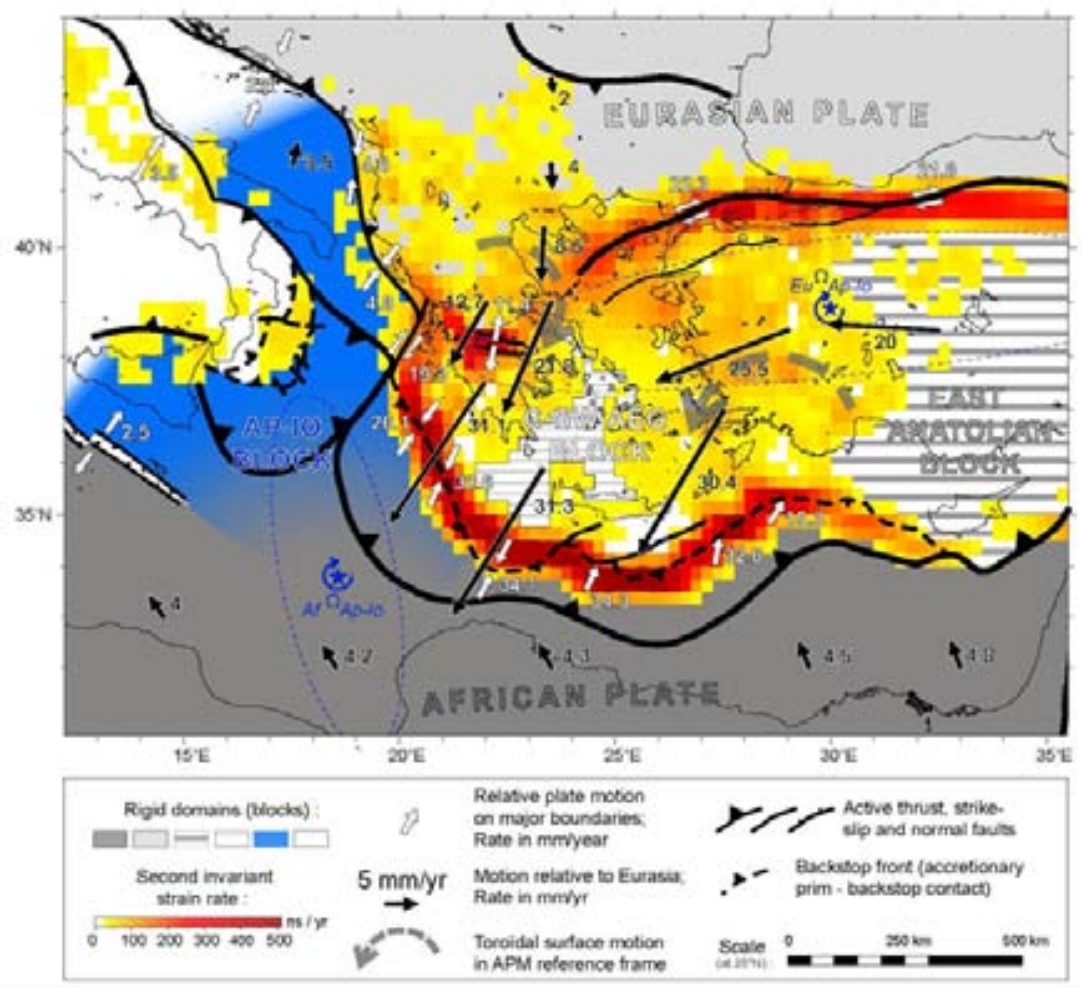

Fig. 11. Present-day kinematics and tectonic map encompassing the Central and Eastern Mediterranean, summarizing main results and interpretation

\section{Conclusion}

The examples presented of the application of the space-enabled technologies such as GNSS and InSAR, for study and monitoring of seismogenic zones, show their importance and advantages in establishing of regularities in the development of slow and fast motions in the seismogenic zones, in revealing the developing tectonic processes and namely the accumulation and delivering of tectonic tensions, related to the assessment of seismic hazard and the forecasting of strong earthquakes.

\section{Refferences}

1. Hristoskov, L. Seismology, 2005; 2007 (in Bulgarian).

2. Dimitrov, D. St. Geodetic studies in the seismogenic zones. D.Sc. thesis, 2009.

3. Dimitrov, D. S., J. B. DeChabalier, J.-C. Ruegg, R. Armijo, B. Meyer, and E. Botev, The 1928 Plovdiv sequence (Bulgaria): fault model constrained from geodetic data and surface breaks”, Geophys. J. Int., 2017 (in press). 
4. Vanneste, K., A. Radulov, P. DeMartini., G. Nikolov, T. Petermans, K. Verbeeck, D. Pantosti, T. Camelbeeck, D. Dimitrov, and S. Shanov, Paleoseismologic investigation of the fault that ruptured in the April 14, 1928, Chirpan earthquake (M=6.8), Southern Bulgaria, Journal of Geophysical Research, 2006, 111, B01303.

5. Meyer, B., M. Sebrier, and D. Dimitrov, Rare destructive earthquakes in Europe: The 1904 Bulgaria event case”, Earth and Planet. Sci. Lett., 2007, 253, 3-4, 485-496.

6. Ilieva, M., P. Briole, A. Ganas, D. Dimitrov, P. Elias, A. Mouratidis, and R. Charara, InSAR investigation and fault plane modelling of $14^{\text {th }}$ of August 2003 Lefkada Island (Greece) earthquake, Tectonophysics, 2016, 693, A, 47-65.

7. Darwin, C., Geological observation on coral reefs, volcanic island and on South America, Londres, 1851, 768 p.

8. Lomnitz, C., Grandes terremotos y tsunamis en Chile durante el periodo 1535-1955, Geofis. Panamericana, 1971, 1, 151-178.

9. Ruegg, J. C., A. Rudloff, C. Vigny, R. Madariaga, J. B. de Chabalier, J. Campos, E. Kausel, S. Barrientos, and D. Dimitrov, Interseismic strain accumulation measured by GPS in the seismic gap between Constitución and Concepcion in Chile, PEPI, 2009, 5140, 78-85.

10. Kanamori, H., Earthquake Hazard Mitigation and Real-Time Warnings of Tsunamis and Earthquakes, Pure and Applied Geophysics, 2015, 172, 2335-41.

11. Pérouse, E., N. Chamot-Rooke, A. Rabaute, P. Briole, F. Jouanne, I. Georgiev, and D. Dimitrov, Bridging onshore and offshore present-day kinematics of central and eastern Mediterranean: Implications for crustal dynamics and mantle flow, Geochemistry, Geophysics, Geosystems (G3), 2012, 13, Q09013, 25.

12. Dimitrov, D. Application of space technologies for studies and monitoring of seismogenic zones, Aerospace Research in Bulgaria. 2016, 28, 67-76.

\title{
КОСМИЧЕСКИ ТЕХНОЛОГИИ ПРИ ИЗСЛЕДВАНЕ И МОНИТОРИНГ НА СЕИЗМОГЕННИ ЗОНИ
}

\section{Д. Димитров}

\begin{abstract}
Резюме
В настоящата статия са представени резултатите от изследвания, осъществени от автора или от колективи под негово ръководство или с негово участие, в различни сеизмогенни зони у нас и по света. Представените примери от приложението на космическите технологии GNSS (Global Navigation Satellite System) и InSAR (Interferometry Synthetic Aperture Radar) за изследване и мониторинг на сеизмогенни зони показват значението и предимствата на тези методи при установяане на закономерности в развитието на тектонските процеси на натрупване и освобождаване на напрежения в сеизмогенните зони, свързани с оценката на сеизмичният риск и средносрочното прогнозиране на силни земетресения.
\end{abstract}

